\title{
Of Cardiology \\ VALUE OF ST-SEGMENT ELEVATION IN LEAD aVR IN NON ST- \\ ELEVATION MYOCARDIAL INFARCTION/UNSTABLE ANGINA IN PREDICTING DISEASE EXTENT, SEVERITY AND OUTCOMES.
}

\section{Dr. Naga Narasimha Reddy M \\ Dr. Vanajakshamma V}

Dr. Rajasekhar D
Assistant Professor, Department of Cardiology, Sri Venkateswara Institute of Medical Sciences, Tirupati, Andhra Pradesh, India.

Professor, Department of Cardiology, Sri Venkateswara Institute of Medical Sciences, Tirupati, Andhra Pradesh, India. *Corresponding Author Senior Professor \& Head, Department of Cardiology, Sri Venkateswara Institute of Medical Sciences, Tirupati, Andhra Pradesh, India.

Assistant Professor, Department of Cardiology, Sri Venkateswara Institute of Medical Sciences, Tirupati, Andhra Pradesh, India.

Dr. Ravindra Dev V Senior Resident,Department of Cardiology, Sri Venkateswara Institute of Medical Sciences, Tirupati, Andhra Pradesh, India.

ABSTRACT Background: ST -segment elevation (STE) in lead aVR has been associated with three vessel disease and left main coronary stenosis in acute coronary syndrome, but prognostic relevance of this finding as an independent predictor in patients with non ST elevation myocardial infarction(NSTEMI) or unstable angina (UA) remains unknown. Methodology: We prospectively evaluated the initial electrocardiogram (ECG) in 112 patients with NSTEMI or UA. ST-elevation in lead aVR was measured. Echocardiography was performed, mitral regurgitation and left ventricular ejection fraction (LVEF) were assessed. Selective coronary angiography was performed at median of 3 days after admission, SYNTAX and Gensini scores were calculated. All the patients were followed up in hospital and 3 months after discharge. Results: Overall, 34 patients (30.3\%) had STE in lead aVR (group A) and remaining 78 patients (68.7\%) had NSTE (Group B). Group A patients had a higher prevalence of lateral leads ST-segment depression $(\mathrm{p}=0.001)$. However, group A peak troponin I $(\mathrm{p}=0.14)$ and $\operatorname{LVEF}(\mathrm{p}=0.22)$ were not significantly different, but had a higher incidence of mitral regurgitation $(\mathrm{MR})(\mathrm{p}=0.02)$. The incidence of single vessel disease, double vessel disease and triple vessel disease in group A were $41 \%, 29.3 \%$ and $23.5 \%$, whereas in group B they were $49 \%, 33.3 \%$ and $10 \%$ respectively $(\mathrm{p}=0.43, \mathrm{p}=0.67$ and $\mathrm{p}=0.06$ respectively). The mean $\mathrm{SYNTAX}$ score was $24.56 \pm 16.43$ in group A and $19.46 \pm 14.39$ in group $B$ $(p=0.47)$. The mean Gensini score was $64.73 \pm 40.70$ in group A as compared to $46.32 \pm 39.43$ in group B ( $p=0.53$ ). There was no significant difference in 3 months clinical outcomes in the two groups. Conclusion: Our study showed that in NSTEMI/Unstable angina, ST elevation in aVR is associated with ST depression in lateral leads and significant MR. Readmission due to acute coronary syndromes was significantly higher in patients with STE in aVR. However, there was no significant difference in troponin I levels, LVEF, disease extent by Gensini and SYNTAX score between the two groups.

\section{KEYWORDS : ST-elevation; NSTEMI; SYNTAX score; Gensini score; lead aVR.}

\section{INTRODUCTION:}

Lead aVR, is the augmented unipolar right arm lead, whose positive pole is oriented to the right upper side of the heart, but is usually neglected in clinical practice. ${ }^{1,2}$ It has frontal plane vector of -150 degree, oriented directly to right ventricular outflow tract and interventricular septum basal part below the pulmonary and aortic valves. ${ }^{3}$ It also confronts lateral wall and left ventricular apical segment inner side and is opposite to chest leads of v5, v6 and standard limb leads I and II. Usually proximal septal branches of the left anterior descending artery (LAD) supply blood to the basal septum and large conal branch from the right coronary artery (RCA) supplies the right ventricular (RV) outflow tract. Infarction of these areas often cause STsegment elevation (STE) in lead aVR. This finding in combination with other repolarization changes, has been associated with severe coronary artery lesions in patients with acute coronary syndrome (ACS). ${ }^{4-6}$ But limited data suggest that STE in aVR is associated with higher mortality and more extensive coronary artery disease in the setting of non-ST elevation ACS

However, different studies showed the association between STE in lead aVR and the risk of triple vessel disease (TVD) and the left main coronary stenosis, but prognostic and echocardiographic relevance of lead aVR STE as an independent predictor in patients with non STelevation myocardial infarction (NSTEMI)/unstable angina (UA) remains unknown.

The current study was aimed to investigate the predictive value of STE in lead aVR recorded in patients with NSTEMI/UA in the evaluation of atherosclerosis extent and severity by modified Gensini score, SYNTAX score, high risk echocardiographic findings like mitral regurgitation (MR), left ventricular ejection fraction (LVEF), association with peak troponin I levels and 3 months clinical outcomes.

\section{MATERIALS \& METHODS:}

This single centre, prospective study was conducted in the department of Cardiology, SVIMS, Tirupati from June 2017 to May 2018. Study was approved by the Institutional Ethics Committee of SVIMS, Tirupati. A written informed consent was obtained from all the study participants. A total of 112 patient s with NSTEMI or UA were studied. Patients were divided into two groups based on the ECG findings documented when experiencing chest pain with STE in lead aVR or without STE in lead aVR.

Inclusion criteria: Patients aged $>18$ years admitted in the department of Cardiology with confirmed diagnosis of NSTEMI or UA were included in the study.

Exclusion criteria: Patients with ECG features of left ventricular hypertrophy; STE $>0.1 \mathrm{mV}$ in leads other than aVR or V1; left bundle branch block; Pre-excitation syndrome; known valvular or congenital heart disease; cardiomyopathies; pregnant women; not willing to participate were excluded.

Data Collection: Baseline clinical and demographic characteristics were obtained from all patients. A detailed physical examination was performed including past medical history. 12-lead ECG was taken using a MORTARA ELI 250 machine. Patients were divided into two groups, based on the ECG findings documented when experienced chest pain with STE in lead aVR or without STE in lead aVR. STelevation in lead aVR was considered significant if it was $>0.05 \mathrm{mV}$. ST-segment shifts were assessed at $80 \mathrm{~ms}$ after the J point for ST segment depression and at the $20 \mathrm{~ms}$ after this point for STE applying the prior TP segment at baseline.

Comprehensive two-dimensional transthoracic echocardiography including M-mode and, Doppler echocardiography, was performed by an experienced cardiologist before conventional coronary 
angiography (CCA), using Philips iE-33 Echocardiography machine with a 3.6 MHZ transducer. Measurements were performed according to the American Society of Echocardiography guidelines. ${ }^{9-11}$ The left ventricular ejection fraction (LVEF) defined as the end-diastolic volume (EDV) minus the end-systolic volume (ESV) divided by the EDV from biplane apical two- and four chamber views using the modified Simpson's technique. Also MR severity, diastolic dysfunction and pulmonary artery pressure (PAP) were assessed, MR graded on the following 4 levels: none, mild, moderate, and severe. Diastolic dysfunction graded as none (0), mild (I), moderate (II), and severe(III)

All the patients underwent selective Coronary Angiography (CAG). Assessment of angiographic lesion severity were done by modified Gensini score and SYNTAX score. All the patients were followed up in hospital and for 3 months after discharge.

Statistical Analysis: Data was collected in pre-designed Microsoft excel spread sheets. Data was presented as mean and standard deviation for continuous variables and frequencies with percentages for categorical variables. Differences observed were tested for significance with Independent Student's t-test for continuous data and with Fischer's exact test for categorical data. All the statistical analysis was performed with SPSS Version 20.0. (IBM, Somers, NY, USA). A p-value of $\leq 0.05$ was considered as significant.

\section{RESULTS:}

Out of 112 patients, ST elevation (STE) in lead aVR was present in 34 $(30.3 \%)$ patients and 78 patients $(68.7 \%)$ had no ST elevation in lead aVR. Mean age of the study population was $58.9 \pm 10.7$ (range: $34-82$ years). Majority of the patients were in 50-60 years age group. 77 $(68.7 \%)$ were males and $35(31.3 \%)$ were females. The most common risk factor for $\mathrm{CAD}$ was diabetes mellitus, followed by hypertension and smoking. 58\% Diabetics were in STE in aVR group, 32\% were in without STE in aVR group. STE in lead aVR was significantly associated with DM in STE lead aVR group. There was a statistically significant higher prevalence of lateral ST depression in STE group. Baseline ECG characteristics were shown in table-1.

Table-1: Baseline Electrocardiographic characteristics.

\begin{tabular}{|l|l|l|l|}
\hline & $\begin{array}{l}\text { Without STE } \\
\text { in aVR (n=78) }\end{array}$ & $\begin{array}{l}\text { ST elevation in } \\
\text { aVR (n=34) }\end{array}$ & p-value \\
\hline $\begin{array}{l}\text { Negative T waves } \\
\text { without 'ST' } \\
\text { depression }\end{array}$ & $23(29 \%)$ & $6(17.7 \%)$ & 0.20 \\
\hline $\begin{array}{l}\text { Inferior 'ST' } \\
\text { segment depression }\end{array}$ & $5(6.4 \%)$ & $4(12 \%)$ & 0.32 \\
\hline $\begin{array}{l}\text { Anterior 'ST' } \\
\text { segment depression }\end{array}$ & $2(2.5 \%)$ & $1(2 \%)$ & 0.66 \\
\hline $\begin{array}{l}\text { Lateral 'ST' } \\
\text { segment depression }\end{array}$ & $18(23 \%)$ & $17(50 \%)$ & $0.004^{*}$ \\
\hline $\begin{array}{l}\text { Without 'ST' } \\
\text { changes in leads } \\
\text { other than aVR }\end{array}$ & $37(47 \%)$ & $10(29.5 \%)$ & 0.08 \\
\hline
\end{tabular}

Fischer's exact test. *indicates significant p-value.

Echocardiographic characteristics were shown in table-2. STE in lead aVR was strongly associated with moderate and severe MR and higher incidence of MR. However peak troponin-I $(p=0.14)$ and $\operatorname{LVEF}(\mathrm{p}=0.10)$ were not significantly different.

Table-2: Echocardiograhic data.

\begin{tabular}{|c|c|c|c|}
\hline & $\begin{array}{c}\text { Without STE in } \\
\text { aVR (n=78) }\end{array}$ & $\begin{array}{c}\text { ST elevation in } \\
\text { aVR (n=34) }\end{array}$ & p-value \\
\hline Troponin I & $1.23 \pm 1.90$ & $1.56 \pm 1.75$ & 0.14 \\
\hline LVEF\% & $53.84 \pm 7.20$ & $53.94 \pm 7.21$ & 0.10 \\
\hline No MR & $57(73.1 \%)$ & $18(52.9 \%)$ & 0.21 \\
\hline Mild MR & $14(17.9 \%)$ & $4(11.8 \%)$ & 0.20 \\
\hline Moderate MR & $06(7.7 \%)$ & $9(26.5 \%)$ & $0.007^{*}$ \\
\hline Severe MR & $01(1.3 \%)$ & $3(8.8 \%)$ & $0.004 *$ \\
\hline
\end{tabular}

LVEF: left ventricular ejection fraction; MR: mitral regurgitation. Fischer's exact test. *indicates significant p-value.

Cardiac catheterization data: The incidence of single vessel disease, double vessel disease, triple vessel disease in STE group was 41.2\%,
$29.4 \%, 23.5 \%$ and in Non STE group it was 52.6\%, 33.3\%, $10.3 \%$ respectively $(\mathrm{p}=0.43, \mathrm{p}=0.67$ and $\mathrm{p}=0.06$ respectively). Patients with STE in lead aVR were more likely to have TVD but it was not statistically significant. Genisini and SYNTAX score were not significantly associated with this group. Cardiac catheterization data was summarized in table-3.

Table-3: Cardiac catheterization data.

\begin{tabular}{|c|c|c|c|}
\hline & $\begin{array}{c}\text { Without STE in } \\
\text { aVR }(\mathbf{n = 7 8 )}\end{array}$ & $\begin{array}{c}\text { ST elevation in } \\
\text { aVR }(\mathbf{n}=\mathbf{3 4})\end{array}$ & -value \\
\hline SVD & $41(52.6 \%)$ & $14(41.2 \%)$ & 0.43 \\
\hline 2VD & $26(33.3 \%)$ & $10(29.4 \%)$ & 0.67 \\
\hline TVD & $08(10.3 \%)$ & $08(23.5 \%)$ & 0.06 \\
\hline Left Main disease & $03(3.8 \%)$ & $02(5.9 \%)$ & 0.62 \\
\hline Gensini Score & $46.32 \pm 39.43$ & $64.73 \pm 40.70$ & 0.53 \\
\hline SYNTAX Score & $19.46 \pm 14.39$ & $24.56 \pm 16.43$ & 0.47 \\
\hline
\end{tabular}

SVD: Single vessel disease; 2VD: Double vessel disease; TVD: Triple vessel disease.

Management: $53 \%$ of STE in lead aVR patients were managed with optimal medical management (OMT), but it was not statistically significant. PTCA was done in $75.6 \%$ of non STE aVR group (table-4). However it was not significantly associated.

Table-4: Management patterns.

\begin{tabular}{|l|l|l|l|}
\hline & $\begin{array}{l}\text { Without STE in } \\
\text { aVR }(\mathbf{n}=\mathbf{7 8})\end{array}$ & $\begin{array}{l}\text { ST elevation in aVR } \\
(\mathbf{n}=\mathbf{3 4})\end{array}$ & $\begin{array}{l}\mathbf{p}- \\
\text { value }\end{array}$ \\
\hline $\begin{array}{l}\text { Optimal Medical } \\
\text { Treatment }\end{array}$ & $11(14.2 \%)$ & $18(53.0 \%)$ & 0.84 \\
\hline PTCA & $59(75.6 \%)$ & $14(41.1 \%)$ & 0.93 \\
\hline CABG & $08(10.2 \%)$ & $02(5.9 \%)$ & 0.65 \\
\hline
\end{tabular}

PTCA: Percutaneous transluminal coronary angioplasty; CABG: Coronary artery bypass grafting.

In hospital and three-month outcome: All of deaths occurred within the group of STE in aVR. During follow-up readmission due to ACS was high in STE in aVR group. (table-5)

Table-5: In hospital and three-month outcome.

\begin{tabular}{|l|l|l|l|}
\hline & $\begin{array}{l}\text { Without STE in aVR } \\
(\mathbf{n = 7 8 )}\end{array}$ & $\begin{array}{l}\text { ST elevation in } \\
\text { aVR (n=34) }\end{array}$ & p-value \\
\hline Mortality & 0 & $2(5.9 \%)$ & $0.001^{*}$ \\
\hline $\begin{array}{l}\text { Readmission } \\
\text { due to ACS }\end{array}$ & $12(15.4 \%)$ & $6(17.6 \%)$ & $0.05^{*}$ \\
\hline CCF & $4(5.1 \%)$ & $4(11.7 \%)$ & 0.21 \\
\hline
\end{tabular}

ACS: Acute coronary syndrome; CCF: Congestive cardiac failure. Fischer's exact test. *indicates significant $p$-value.

\section{DISCUSSION:}

ECG has a considerable value in the prognostic classification and predicting disease extent in NSTEMI or unstable angina patients. Few studies with inconsistent data had assessed the prognostic aspect of lead aVR. Our study showed that STE in lead aVR was significantly associated with MR and readmission due to ACS in patients with NSTEMI or unstable angina. Furthermore we showed that this ECG pattern was associated with triple vessel disease.

In our study, there was a higher prevalence of lateral ST depression in STE in lead aVR group which was statistically significant. Nabati et $\mathrm{al}^{12}$ study showed that STE in lead aVR is independently associated. With LVEF. In our study LVEF was not independently associated. Our study showed that aVR STE is significantly associated with moderate and severe MR. Therefore, this group are even more likely to have adverse outcomes. Few prior studies evaluated MR in patients with aVR STE.

Pérez de Isla $L$ et $\mathrm{al}^{13}$ investigated functional MR after a first non-STE in 279 patients and followed them. They showed that MR was found as an independent predictor of $\mathrm{CHF}$ development $(\mathrm{HR}=1.8 ; 95 \% \mathrm{CI}=$ $1.1-3.1 ; \mathrm{p}=0.02)$ and CHF development or cardiac death $(\mathrm{HR}=2.1$; $95 \% \mathrm{CI}=1.3-3.3 ; \mathrm{p}=0.01)$ during long-term follow-up. Thus, the detection of MR by Doppler echocardiography after a first episode of NSTSEACS is crucial. 
Kosuge et $\mathrm{al}^{14}$ found that in patients with NSTEMI, STE in lead aVR was a useful predictor of LMCA or triple vessel disease. Nabati et $\mathrm{al}^{12}$ showed that STE in lead aVR was independently associated with atherosclerosis severity and higher Gensini score, but in our study Gensini and SYNTAX score did not show a significant difference between the two groups.

Szymański FM et $\mathrm{al}^{15}$ studied in 229 patients with NSTEMI/unstable angina. They found patients with aVR STE compared to patients without aVR STE had higher death rates in the low- and intermediaterisk groups by TIMI risk score. Taglieri $\mathrm{N}$ et $\mathrm{al}^{16}$ found that $\mathrm{ST}$ deviation plus STE in lead aVR was a stronger independent predictor of cardiovascular death (HR: $2.29,95 \%$ CI: $1.44-3.64, \mathrm{p}<0.001$ ) than isolated ST deviation (HR: $1.52,95 \%$ CI: 0.98-2.36, $\mathrm{p}=0.06$ ).

Barrabes et $\mathrm{al}^{17}$ studied patients with a first acute myocardial infarction without STE in leads other than aVR or V1. The rates of in-hospital death in patients without $(\mathrm{n}=525)$ and with 0.05 to $0.1 \mathrm{mV}(\mathrm{n}=116)$ or $>$ or $=0.1 \mathrm{mV}(\mathrm{n}=134)$ of STE in lead aVR were $1.3 \%, 8.6 \%$, and $19.4 \%$, respectively $(\mathrm{P}<0.001)$. The rates of recurrent ischemic events and heart failure during hospital stay also increased in a stepwise fashion among the groups. Our study showed that STE in lead aVR was significantly associated with readmission due to ACS. In our study, all deaths (two) occurred in STE in lead aVR group only.

Limitations: Small sample size and single center study.

\section{CONCLUSION:}

Our study showed that in NSTEMI/Unstable angina, ST elevation in $\mathrm{aVR}$ is associated with ST depression in lateral leads and significant MR. Readmission due to ACS is significantly higher in patients with $\mathrm{STE}$ in aVR. However, there is no significant difference in troponin-I levels, LVEF, disease extent by Gensini and SYNTAX score in the two groups.

\section{Acknowledgements: None. \\ Source of funding: None. \\ Conflict of interest: None.}

\section{REFERENCES:}

1. George A, Arumugham PS, Figueredo VM. aVR - the forgotten lead. Exp Clin Cardiol. 2010; 15(2): e36-e44

2. Haim M, Benderley M, Hod H, et al. The outcome of patients with a first non-Q wave acute myocardial infarction presenting with ST segment depression, ST segment elevation, or no ST deviations on the admission electrocardiogram. Int J Cardiol. 1998; 67;39-46.

3. Wong CK, Gao W, Stewart RA, et al. aVR ST elevation: an important but neglected sign in ST elevation acute myocardial infarction. Eur Heart J 2010;31.

4. Kanei Y. ST-segment depression in aVR as a predictor of culprit artery and infarct size in acute inferior wall ST segment elevation myocardial infarction. J Electrocardiol 2010; 43:132-35

5. Menown IB, Adgey AA. Improving the ECG classification of inferior and lateral myocardial infarction by inversion of lead aVR. Heart 2000; 83: 657-60.

6. Kosuge M. ST-segment depression in lead aVR: a useful predictor of impaired myocardial reperfusion in patients with inferior acute myocardial infarction. Chest 2005; 128:780-86.

7. Tamura A. Significance of lead aVR in acute coronary syndrome. World J Cardiol 2014; 6(7): 630-637

8. Rostof P, Piwowarska W. ST segment elevation in lead aVR and coronary artery lesions in patients with acute coronary syndrome. Kardiol pol 2006; 64:8-14.

9. ZoghbiWA. American society of Echocardiography. Recommendations for evaluation of the severity of native valvular regurgitation with two- dimensional and Doppler of the severity of native valvular regurgitation with two-
echocardiography. JAm Soc Echocardiogr 2003; 16:777-802.

10. Nagueh SF. Recommendations for the evaluation of left ventricular diastolic function by echocardiography. Eur J Echocadiogr 2009; 10:165-93.

11. RudskiLG. Guidelines for the echocardiographic assessment of the right heart in adults: a report from the American society of Echocardiography endorsed by the European Association of Echocardiography, a registred branch of the European society of cardiology, and the Canadian society of Echocardiography. J Am Soc Echocardiogr 2010;23:685-713.

12. Nabati M. ST-Segment elevation in lead aVR in the setting of acute coronary syndrome. Acta Cardiol 2016;71(1):47-54

13. Pérez de Isla L. Functional mitral regurgitation after a first non-ST-segment elevation acute coronary syndrome: contribution to congestive heart failure. Eur Heart J. 2007; 28(23):2866-72

14. Kosuge M. Predictors of left main or three-vessel disease in patients who have acute coronary syndromes with non-ST-segment elevation. Am J Cardiol 2005; 95:13669.

15. Szymański FM, Grabowski M, Filipiak KJ, Karpiński G, Opolski G. Admission STsegment elevation in lead aVR as the factor improving complex risk stratification in acute coronary syndromes. Am J Emerg Med. 2008; 26(4):408-12.

16. Taglieri N. Short- and long-term prognostic significance of ST-segment elevation in lead aVR in patients with non-ST-segment elevation acute coronary syndrome. Am J Cardiol. 2011; 108(1):21-8.

17. Barrabés JA, Figueras J, Moure C, Cortadellas J, Soler-Soler J. Prognostic Value of Lead aVR in Patients With a First Non-ST-Segment Elevation Acute Myocardial Infarction. Circulation. 2003; 108:814-19. 